\title{
Efeito de doses de boro no crescimento vegetativo de girassol em diferentes classes de solos $^{1}$
}

\author{
Manoel Euba Neto², Vânia da Silva Fraga³, Bruno de Oliveira Dias ${ }^{4}$, Jacob Silva Souto
}

\section{RESUMO}

A baixa disponibilidade de boro (B) no solo é um dos fatores que mais limita a produção do girassol, planta oleaginosa caracterizada por ampla adaptabilidade climática. O objetivo desta pesquisa foi avaliar a influência de doses de boro, aplicadas em distintas classes de solos, no desenvolvimento do girassol cultivar Hélio 863. As amostras foram coletadas na camada de 0-20 cm dos solos: Argissolo Acinzentado (PAC); Argissolo VermelhoAmarelo (PVA); Neossolo Litólico (RL); Argissolo Vermelho eutrófico (PVe); Neossolo Flúvico (RY) e Vertissolo Háplico (VX). O delineamento experimental foi em blocos casualizados, em esquema fatorial 6 x 4 (solos x doses), com quatro repetições. A unidade experimental foi representada por uma planta por vaso. Os solos apresentaram efeito significativo ( $\mathrm{p}<0,01$ ) sobre todos os parâmetros de crescimento estudados. As plantas de girassol cultivadas nos solos RY, VX, PAC e RL apresentaram a maior área foliar, os maiores capítulos, o maior teor de boro foliar e maior número de folhas e altura de plantas, respectivamente. A adubação com boro não influenciou a produção de fitomassa seca do girassol cv. Hélio 863.

Palavras-chave: nutrição mineral, Helianthus annuus L., micronutriente, azometina-H, área foliar.

\section{ABSTRACT \\ Effect of boron levels in vegetative growth of sunflower in different soil classes}

The low availability of boron (B) in the soil is one of the limiting factors for the production of sunflower, which is an oleaginous plant characterized by broad climatic adaptability. The objective of this study was to evaluate the influence of boron rates applied in different soil classes on the development of sunflower cultivar Helium 863. The samples were collected in the layer 0-20 cm of the soil classes Gray Argisol - GL, Red Yellow Argisol - RYA, Litholic Neosol - LN, Eutrophic Red Argisol - ERA, Fluvic Neosol - FN and Haplic Vertisol - HV. The experiment was arranged in a randomized block 4 x 6 factorial (soils x doses) design, with four replications. The experimental unit was represented by one plant per pot. The soils showed significant effect $(\mathrm{p}<0.01)$ for all growth parameters studied. The sunflower plants grown in the soils FN, HV, GL and LN showed the highest leaf area, the largest inflorescence diameter, the highest levels of foliar boron, largest number of leaves and highest plant height, respectively. Fertilization with boron did not influence the production of dry matter of sunflower cv. Helium 863.

Key words: mineral nutrition, Helianthus annuus L., micronutrient, azomethine-H, leaf area

\footnotetext{
Recebido para publicação em 27/04/2012 e aprovado em 14/06/2013.

${ }^{1}$ Parte da dissertação de mestrado do primeiro autor apresentada à Universidade Federal da Paraíba.Trabalho financiado pela Universidade Estadual do Maranhão/UEMA. ${ }^{2}$ Licenciado em Química, Mestre. Departamento de Química e Biologia, Universidade Estadual do Maranhão, Campus Caxias, Praça Duque de Caxias, s/n, Centro, 65600-000, Caxias, Maranhão, Brasil. (31) 3521-3988. meuban @ hotmail.com (autor correspondente).

${ }^{3}$ Química Industrial, Doutora. Departamento de Solos e Engenharia Rural, Universidade Federal da Paraíba, Campus II, Centro de Ciências Agrárias, Cidade Universitária, s/n, 58.397-000, Caixa postal 12.168, Areia, Paraíba, Brasil. vfraga@cca.ufpb.br

${ }^{4}$ Engenheiro-Agrônomo, Doutor. Departamento de Solos, Universidade Federal do Piauí, Campus Profa. Cinobelina Elvas, BR 135, Km 03, Planalto Horizonte/Cibrazem, 64.900000, Bom Jesus, Piauí, Brasil. b2dias@yahoo.com.br

5 Engenheiro-Agrônomo, Doutor. Unidade Acadêmica de Engenharia Florestal, Centro de Saúde e Tecnologia Rural, Universidade Federal de Campina Grande, Campus de Patos, Avenida Universitária, s/n, Bairro Santa Cecília - Caixa Postal 61, 58.700-970, Patos, Paraíba, Brasil. jacob_souto@uol.com.br
} 


\section{INTRODUÇÃO}

O girassol é uma das principais plantas oleaginosas do mundo, que se caracteriza por ampla adaptabilidade climática (Aquino et al., 2011). Assim, um importante aspecto a ser considerado é o de os cultivares de girassol poderem exibir diversidade de comportamento, de acordo com a região de cultivo, da época de semeadura e, principalmente, da interação do genótipo com o meio ambiente (Porto et al., 2007), influenciando diretamente a produção de grãos (Afférri et al., 2008).

No semiárido brasileiro, nos últimos anos, tem-se verificado aumento da área cultivada com girassol e, com a finalidade de tornar cada vez mais conhecido o comportamento dessa cultura, diversos cientistas têm estudado o crescimento, desenvolvimento e produção do girassol, nos mais diferentes tipos de solos desta região (Oliveira et al., 2012; Santos Júnior et al., 2011; Travassos et al., 2011).

Considerando-se os fatores ambientais, como $\mathrm{pH}$, textura do solo, umidade, temperatura, matéria orgânica, entre outros, a baixa disponibilidade de boro (B) no solo é um dos fatores que mais limita a produção do girassol (Hu \& Brown, 1997), que, apesar de altamente exigente quanto a este nutriente, tem reduzida eficiência no seu aproveitamento. Por consequência, a deficiência de B afeta o desenvolvimento da planta, causando, por exemplo, inibição do crescimento radicular, das folhas jovens, que se tornam endurecidas e necróticas (Souza et al., 2004), resultando em diminuição da área foliar (AF), podendo ainda ocorrer abortamento floral e queda do capítulo (Dechen \& Nachtigall, 2006), culminando com perda de produção (Souza et al., 2004).

$\mathrm{O}$ adequado suprimento de $\mathrm{B}$ influencia a quantidade de material assimilado pelas folhas e o tamanho do aparelho fotossintetizante (Monteiro et al., 2005). Assim, para a elevação do potencial produtivo, faz-se necessário o fornecimento de nutrientes em qualidade e quantidades adequadas, evitando-se a falta ou o excesso de um determinado elemento (Prado \& Leal, 2006).

O crescimento e o desenvolvimento do girassol constituem produto da interação dos fatores genéticos e ambientais; assim, quantificar o que favorece os processos de crescimento e, ou, desenvolvimento, possibilita a otimização de técnicas utilizadas na produção (Fagundes et al., 2007). Neste sentido, a nutrição mineral é um importante fator, sendo o boro o micronutriente exigido em maior quantidade pela cultura do girassol. Assim, o crescimento e desenvolvimento desta planta é altamente dependente da disponibilidade de boro, uma vez que este elemento está relacionado, por exemplo, à frutificação e formação do capítulo, dentre outros processos (Santos et al., 2010).
Portanto, níveis adequados de boro no solo para cultivo de girassol favorece a melhoria das características como fitomassa da parte aérea e da raiz, número de folhas, altura de planta, diâmetro do capítulo e área foliar, que dependem das condições edafoclimáticas, do cultivar e da densidade populacional, dentre outros fatores (Monteiro et al., 2005).

O objetivo desta pesquisa foi avaliar a influência de doses de boro, em distintas classes de solos, no desenvolvimento do girassol cultivar Hélio 863.

\section{MATERIAL E MÉTODOS}

$\mathrm{O}$ experimento foi conduzido em ambiente protegido com plástico transparente, no Centro de Ciências Agrárias - CCA, da Universidade Federal da Paraíba - UFPB, no município de Areia, de janeiro a março de 2010. Os vasos foram dispostos em bancadas cimentadas, com $0,90 \mathrm{~cm}$ de altura, e irrigados diariamente com água destilada, para repor as perdas por evapotranspiração. O controle da irrigação foi feito por meio da pesagem diária dos vasos.

O delineamento experimental foi em blocos casualizados, em esquema fatorial $6 \times 4$ (solos $\mathrm{x}$ doses), com quatro repetições. A unidade experimental foi representada por uma planta por vaso.

Foram utilizadas amostras de seis classes de solos representativos do Estado da Paraíba, classificados, de acordo com a Embrapa (2006), como: Argissolo Acinzentado (PAC); Argissolo Vermelho-Amarelo (PVA); Neossolo Litólico (RL); Argissolo Vermelho eutrófico (PVe); Neossolo Flúvico (RY) e Vertissolo Háplico (VX).

As amostras dos solos foram coletadas na camada superficial de $0-20 \mathrm{~cm}$, secadas ao ar e passadas em peneira com abertura de malha de 2,0 $\mathrm{mm}$. Em seguida, foram realizadas análises laboratoriais para a caracterização química e física desses solos (Tabelas 1 e 2), conforme metodologias descritas em Embrapa (1997). A extração do boro foi realizada pelo método de extração com solução $0,005 \mathrm{~mol} \mathrm{~L}^{-1}$ de cloreto de bário $\left(\mathrm{BaCl}_{2} \cdot 2 \mathrm{H}_{2} \mathrm{O}\right)$, submetida a aquecimento com radiação de micro-ondas, nas potências de $700 \mathrm{~W}$ e $490 \mathrm{~W}$, por 4 e 5 minutos, sucessivamente, enquanto a determinação do teor de B nos solos foi realizada por meio de técnica colorimétrica, utilizando-se o reagente azometina-H (Raij et al., 2001).

Avaliou-se a necessidade de calagem, para elevação dos teores de $\mathrm{Ca}^{2+} \mathrm{e} \mathrm{Mg}^{2+}$, pelo método da saturação por bases (Ribeiro et al., 1999). Verificada a necessidade de calagem, fez-se então a correção de acidez com uma mistura de carbonato de cálcio $\left(\mathrm{CaCO}_{3}\right)$ e de cloreto de magnésio $\left(\mathrm{MgCl}_{2} \cdot 6 \mathrm{H}_{2} \mathrm{O}\right)$, em uma relação molar de 3:1, para o solo PAC; o solo PVA recebeu apenas $\mathrm{CaCO}_{3}$ e os solos $\mathrm{PVe}$ e $\mathrm{RY}$ receberam apenas $\mathrm{MgCl}_{2} \cdot 6 \mathrm{H}_{2} \mathrm{O}$, posto em incubação por três meses, com uma quantidade de água cor- 
respondente a 50\% da porosidade total de cada solo. Decorrido o período de incubação, foram aplicadas as doses de $\mathrm{B}$, na forma de ácido bórico $\left(\mathrm{H}_{3} \mathrm{BO}_{3}\right)$, de pureza analítica (p.a.), em solução, na concentração de 0,$0 ; 0,50 ; 1,00$ e $2,00 \mathrm{mg} \mathrm{dm}^{-3}$ nos solos. A semeadura do girassol foi realizada em vasos plásticos contendo $3,0 \mathrm{dm}^{3}$ de solo, os quais foram adubados com macro e micronutrientes um dia antes da semeadura. A adubação por vaso, idêntica para todos os tratamentos, com exceção de $\mathrm{B}$, foi de: 50 $\mathrm{mg} \mathrm{dm}{ }^{-3}$ de $\mathrm{N}\left[\mathrm{CO}\left(\mathrm{NH}_{2}\right)_{2}\right] ; 60 \mathrm{mg} \mathrm{dm}^{-3}$ de $\mathrm{Pe} \mathrm{K}\left(\mathrm{KH}_{2} \mathrm{PO}_{4}\right)$; $3,7 \mathrm{mg} \mathrm{dm}^{-3}$ de $\mathrm{Mn}\left(\mathrm{MnSO}_{4} \cdot \mathrm{H}_{2} \mathrm{O}\right) ; 1,33 \mathrm{mg} \mathrm{dm}^{-3}$ de $\mathrm{Cu}$ $\left(\mathrm{CuSO}_{4} \cdot 5 \mathrm{H}_{2} \mathrm{O}\right) ; 4,0 \mathrm{mg} \mathrm{dm}^{-3} \mathrm{de} \mathrm{Zn}\left(\mathrm{ZnSO}_{4} \cdot 7 \mathrm{H}_{2} \mathrm{O}\right)$ e $0,2 \mathrm{mg}$ $\mathrm{dm}^{-3}$ de $\mathrm{Mo}\left[\left(\mathrm{NH}_{4}\right) 6 \mathrm{Mo}_{7} \mathrm{O}_{24} \cdot 4 \mathrm{H}_{2} \mathrm{O}\right]$ (Alvarez et al., 2000). Realizaram-se adubações de cobertura aos 15 e 30 dias após a emergência - DAE, aplicando-se em cada vaso 50 $\mathrm{mg} \mathrm{dm}{ }^{-3} \mathrm{de} \mathrm{NeS}\left(\mathrm{NH}_{4}\right)_{2} \mathrm{SO}_{4}$.

Aos 12, 34, 36 e 50 DAE foram avaliados o número de folhas e a altura das plantas. Aos 50 DAE, o diâmetro do capítulo foi medido com paquímetro e a área foliar foi estimada por método direto, com o scanner "Area Meter AM 300". Após a medida do diâmetro do capítulo (DCAP), os mesmos, juntamente com as folhas e o caule, cortados rente ao solo, foram acondicionados, separadamente, para avaliação dos teores de B; sendo os capítulos e os caules em sacos de papel e as folhas em sacos plásticos, guardadas sob refrigeração até o momento da leitura no scanner. Após a leitura, as folhas foram transferidas para sacos de papel, para secagem. As raízes foram lavadas em água corrente e, em seguida, enxaguadas com água destilada e acondicionadas em sacos de papel. A parte aérea e as raízes foram levadas para uma estufa de circulação de ar, a $70^{\circ} \mathrm{C}$, onde permaneceram até atingirem peso constante. Após a secagem, a matéria seca da parte aérea (folha, caule e capítulo) e a matéria seca das raízes foram trituradas em moinho tipo Wiley e queimadas em forno "mufla" $\left(550^{\circ} \mathrm{C}-650^{\circ} \mathrm{C}\right)$, para extração do boro, para cuja determinação colorimétrica, utilizou-se o reagente azometina-H (Tedesco et al., 1995).

Os dados obtidos para as doses de B foram submetidos a análises de variância e correlação de Pearson. As médias da massa da matéria seca, da área foliar, do diâmetro dos capítulos, dos teores e conteúdo de boro, do número de folhas e da altura das plantas, nas seis classes de solos, foram comparadas pelo teste de Scott-Knott, a 5\% de probabilidade. Realizaram-se todas as análises por meio dos programas estatísticos SAS/STAT (Sas, 2011) e SISVAR (Ferreira, 2000).

\section{RESULTADOS E DISCUSSÃO}

Pela análise de variância dos parâmetros verifica-se que os solos apresentaram efeito significativo $(\mathrm{p}<0,01)$ sobre a área foliar (AF) e o diâmetro do capítulo (DCAP), e que não houve significância para a AF e o DCAP do girassol, em relação à interação doses de boro (B) e classes de solo (Tabela 3). Esses últimos resultados são concordantes com os obtidos por Bonacin (2002) e Santos Júnior et al. (2011), com o girassol, cultivado em Latossolo Vermelho e em Neossolo regolítico.

Tabela 1. Características químicas das seis classes de solos que constituíram o experimento: Argissolo Acinzentado (PAC); Argissolo Vermelho-Amarelo (PVA); Neossolo Litólico (RL); Argissolo Vermelho eutrófico (PVe); Neossolo Flúvico (RY) e Vertissolo Háplico (VX)

\begin{tabular}{lcccccc}
\hline Característica & PAC & PVe & PVA & RL & RY & VX \\
\hline $\mathrm{pH}\left(\mathrm{H}_{2} \mathrm{O}\right) 1: 2,5$ & 6,09 & 6,25 & 4,78 & 6,92 & 6,75 & 6,75 \\
$\mathrm{~B}\left(\mathrm{mg} \mathrm{dm}^{-3}\right)$ & 0,23 & 0,15 & 0,34 & 0,17 & 0,37 & 0,27 \\
$\mathrm{MO}\left(\mathrm{g} \mathrm{kg}^{-1}\right)$ & 4,38 & 7,46 & 3,59 & 10,1 & 3,19 & 3,59 \\
$\mathrm{~K}^{+}\left(\mathrm{mmol}_{\mathrm{c}} \mathrm{dm}^{-3}\right)$ & 1,00 & 1,90 & 0,90 & 3,50 & 4,80 & 3,10 \\
$\mathrm{Na}^{+}\left(\mathrm{mmol}_{\mathrm{c}} \mathrm{dm}^{-3}\right)$ & 0,90 & 1,80 & 0,90 & 3,30 & 5,00 & 3,20 \\
$\mathrm{Ca}^{2+}\left(\mathrm{mmol}_{\mathrm{c}} \mathrm{dm}^{-3}\right)$ & 10,0 & 52,0 & 2,00 & 33,0 & 367 & 96,0 \\
$\mathrm{Mg}^{2+}\left(\mathrm{mmol}_{\mathrm{c}} \mathrm{dm}^{-3}\right)$ & 3,00 & 3,00 & 5,00 & 11,0 & 8,00 & 34,5 \\
$\mathrm{Al}^{3+}\left(\mathrm{mmol}_{\mathrm{c}} \mathrm{dm}^{-3}\right)$ & 0,00 & 0,00 & 9,00 & 0,00 & 0,00 & 0,00 \\
$\mathrm{H}^{+}+\mathrm{Al}^{3+}\left(\mathrm{mmol}_{\mathrm{c}} \mathrm{dm}^{-3}\right)$ & 17,3 & 20,6 & 20,6 & 0,00 & 4,10 & 12,4 \\
\hline
\end{tabular}

Tabela 2. Características físicas das seis classes de solos que constituíram o experimento: Argissolo Acinzentado (PAC); Argissolo Vermelho-Amarelo (PVA); Neossolo Litólico (RL); Argissolo Vermelho eutrófico (PVe); Neossolo Flúvico (RY) e Vertissolo Háplico (VX)

\begin{tabular}{lcccccc}
\hline Característica & PAC & PVe & PVA & RL & RY & VX \\
\hline Areia total $\left(\mathrm{g} \mathrm{kg}^{-1}\right)$ & 885 & 580 & 442 & 847 & 370 & 499 \\
Limo $\left(\mathrm{g} \mathrm{kg}^{-1}\right)$ & 26 & 276 & 159 & 83 & 365 & 283 \\
Argila $\left(\mathrm{g} \mathrm{kg}^{-1}\right)$ & 89 & 144 & 399 & 70 & 315 & 218 \\
Classe textural & A. & F.A. & F.A.Ar. & A.F. & F.A.A. & F.A.A. \\
\hline
\end{tabular}

A.= areia; A.F.= areia franca; F.A.= franco arenosa; F.A.Ar.= franco argilosa argila; F.A.A.= franco argilo arenosa. 
O teste de médias mostrou maiores valores de área foliar para plantas de girassol cultivadas nos solos RY e $\mathrm{VX}$, diferindo significativamente dos mesmos valores nos demais solos estudados, encontrando-se valor superior em 45\%, em relação à menor média alcançada, que se verificou no solo PVA. Em relação ao DCAP, o maior valor alcançado ocorreu no solo VX, diferindo significativamente dos alcançados nos demais solos estudados, encontrando-se valor superior em 30\%, em relação à menor média alcançada, no solo PAC (Tabela 4).

As maiores áreas foliares e os maiores capítulos ocorreram entre as plantas cultivadas em solos menos intemperizados (RL, RY e VX), exceto no solo PVe; esse solo, entretanto, apresenta em sua constituição o mineral 2:1 ilita, característica comum entre os solos menos desenvolvidos do estudo (Tabela 4). Por conseguinte, de forma geral, os menores DCAP e AF foram observados entre as plantas cultivadas em solos mais intemperizados (PAC, PVAe PVe).

A maior área foliar, $2.031 \mathrm{~cm}^{2}$ planta $^{-1}$, foi observada nas plantas cultivadas no solo RY. Por outro lado, a menor área foliar, correspondente a $932 \mathrm{~cm}^{2}$ planta $^{-1}$, foi observada nas plantas cultivadas no solo PVA (Figura 1).

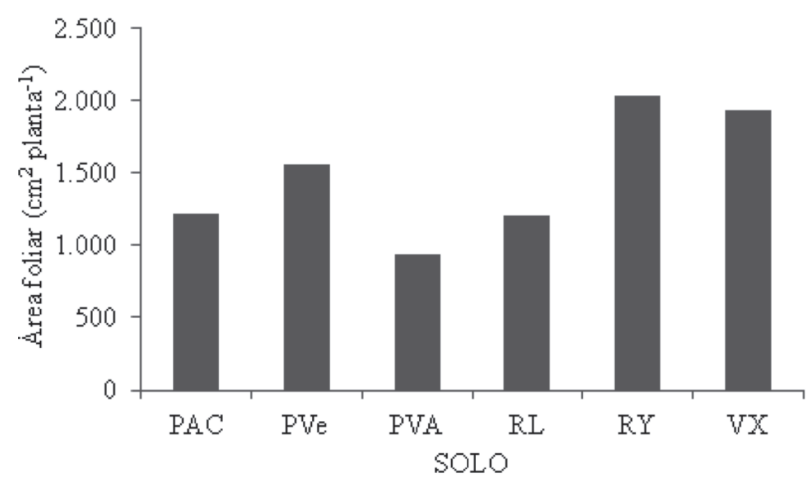

Figura 1. Área foliar total das plantas de girassol aos $50 \mathrm{DAE}$, em seis classes de solos: Argissolo Acinzentado (PAC); Argissolo Vermelho-Amarelo (PVA); Neossolo Litólico (RL); Argissolo Vermelho eutrófico (PVe); Neossolo Flúvico (RY) e Vertissolo Háplico (VX).
Com os resultados obtidos neste estudo, verifica-se a possibilidade de obtenção de maior produção de grãos e de óleo, em função de maiores tamanhos médios de capítulos, ou seja, 7,00; 6,46 e 6,22 cm, nos solos VX; RL e PVe, respectivamente (Figura 2), sendo que, os DCAP dos solos RL e PVe foram estatisticamente iguais (Tabela 4). O diâmetro do capítulo influencia diretamente o número potencial de aquênios, componente essencial da produtividade (Lobo \& Grassi Filho, 2007). Mesmo com o experimento tendo-se encerrado antes da maturação fisiológica da cultura, parcela significativa dos valores médios de diâmetro de capítulos atingiram a ampla faixa de variação de 6 a $50 \mathrm{~cm}$ indicada para o girassol (Figura 2), concordando com os resultados obtidos por Smiderle et al. (2005).

Percebe-se pelo teste de médias maior valor de teor de boro foliar (BF) para o solo PAC; boro no caule (BC) e boro na raiz $(\mathrm{BR})$ para o solo RL e boro no capítulo (BCAP) para o solo PVe; diferindo significativamente dos demais solos estudados, encontrando-se valor superior em 23,4; 27,6; 21,6 e, $33,3 \%$ em relação às menores médias alcançadas. Em oposição, os menores valores de teores de boro, em folha, caule, raiz e capítulo foram 96,08; 44,19; 90,33 e 45,56 mg kg-1 plan$\mathrm{ta}^{-1}$, nos solos RY, PVA, PVA, VX, respectivamente (Tabela 5).

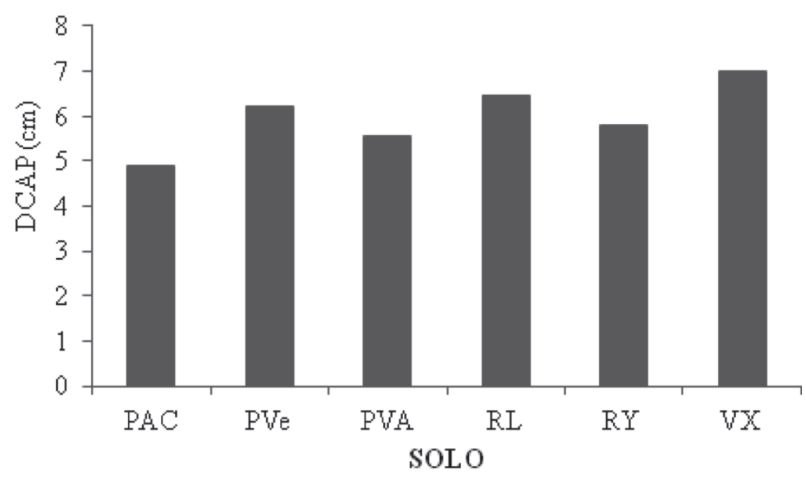

Figura 2. Diâmetro do capítulo das plantas de girassol aos 50 DAE, de acordo com as doses de $\mathrm{B}\left(\mathrm{mg} \mathrm{dm}^{-3}\right)$ em seis classes de solos: : Argissolo Acinzentado (PAC); Argissolo Vermelho-Amarelo (PVA); Neossolo Litólico (RL); Argissolo Vermelho eutrófico (PVe); Neossolo Flúvico (RY) e Vertissolo Háplico (VX).

Tabela 3. Valores de quadrado médio e coeficiente de variação da área foliar (AF) e do diâmetro do capítulo (DCAP) aos 50 dias após a emergência em plantas de girassol, cv. Helio 863, submetidas a quatro doses de boro em seis classes de solos

\begin{tabular}{lcrc}
\hline Fontes de variação & GL & AF & Variáveis \\
\cline { 3 - 4 } & & $110.574,85^{\mathrm{ns}}$ & DCAP \\
\hline Blocos & 3 & $3.100 .098,04^{* *}$ & $0,47^{\mathrm{ns}}$ \\
Solos (S) & 5 & $53.269,21^{\mathrm{ns}}$ & $0,90^{\text {ns }}$ \\
Doses de boro (DB) & 3 & $43.770,36^{\mathrm{ns}}$ & $1,43^{\mathrm{ns}}$ \\
S x DB & 15 & $54.328,37$ & 0,86 \\
Resíduo & 69 & 15,71 & 15,50 \\
\hline C.V.\% & & $1.483,53$ & 5,99 \\
\hline Média & &
\end{tabular}

Rev. Ceres, Viçosa, v. 61, n.3, p. 399-405, mai/jun, 2014 
No entanto, para o Argissolo Acinzentado (PAC), o valor experimental máximo de boro na folha foi de 193,09 mg kg-1 planta $^{-1}$, valor superior em quase o dobro a 99,2 mg kg ${ }^{-1}$ planta $^{-1}$, encontrado por Santos et al. (2010) e Castro et al. (2006). O maior valor, 4,09 mg planta $\mathrm{m}^{-1}, \mathrm{e}, \mathrm{o}$ menor $1,76 \mathrm{mg}$ planta $^{-1}$ de conteúdo de boro na matéria seca total (BMST) foi encontrado nos solos VX e PVA, pedogeneticamente, os solos menos e mais desenvolvidos, respectivamente (Tabela 5).

Verifica-se, na Tabela 5, que maiores teores de B ocorrem nas folhas e nas raizes, talvez pelo fato de o experimento ter sido finalizado aos $50 \mathrm{DAE}$, antes da maturação fisiológica. As maiores taxas de exportação de $\mathrm{B}$ foram nos solos arenosos PAC e RL, tanto na folha como na raiz.

Por meio do teste de médias, constataram-se maiores valores de matéria seca foliar (MSF) (47\%), matéria seca do caule (MSC) $(54,2 \%)$, matéria seca da raiz (MSR) $(70,3 \%)$, matéria seca do capítulo (MSCAP) $(59,6 \%)$ e ma-

Tabela 4. Médias $(\mathrm{n}=16)$ da área foliar $(\mathrm{AF})$ e diâmetro do capítulo (DCAP) em seis classes de solos: Argissolo Acinzentado (PAC); Argissolo Vermelho-Amarelo (PVA); Neossolo Litólico (RL); Argissolo Vermelho eutrófico (PVe); Neossolo Flúvico (RY) e Vertissolo Háplico (VX)

\begin{tabular}{lcc}
\hline \multirow{2}{*}{ Solos } & \multicolumn{2}{c}{ Variáveis } \\
\cline { 2 - 3 } & $\begin{array}{c}\text { Área Foliar } \\
\left(\mathbf{c m}^{2}\right)\end{array}$ & $\begin{array}{c}\text { Diâmetro do Capítulo } \\
(\mathbf{c m})\end{array}$ \\
\hline PAC & $1.217 \mathrm{c}$ & $4,91 \mathrm{~d}$ \\
PVe & $1.584 \mathrm{~b}$ & $6,22 \mathrm{~b}$ \\
PVA & $932 \mathrm{~d}$ & $5,56 \mathrm{c}$ \\
RL & $1.202 \mathrm{c}$ & $6,46 \mathrm{~b}$ \\
RY & $2.031 \mathrm{a}$ & $5,79 \mathrm{c}$ \\
VX & $1.936 \mathrm{a}$ & $7,00 \mathrm{a}$ \\
\hline Erro Padrão & 58,27 & 0,23 \\
\hline
\end{tabular}

Médias seguidas de mesma letra na coluna não diferem entre si pelo teste de Scott-Knott a $5 \%$ de probabilidade. téria seca total (MST) $(54,2 \%)$ para o solo VX, diferindo significativamente dos teores obtidos nos demais solos estudados. Em oposição, as menores médias ocorreram no solo PVA, exceto a de MSCAP, que ocorreu no solo PAC (Tabela 6).

Estimativa dos coeficientes de correlação linear simples, entre a área foliar (AF) e a concentração de B acumulada pela planta, no caule (BC), no diâmetro do capítulo (DCAP), na matéria seca da folha (MSF), na matéria seca total (MST) e o boro presente no solo (BS) mostra correlação positiva, sendo significativa para MSF e MST, e não significativa para os demais. Entre os coeficientes de correlação apresentados, a mais alta correlação foi verificada entre a AF e MST (Tabela 7). Verificou-se também correlação positiva $(0,52)$ e significativa menor que $1 \%$ entre a MST e o DCAP das plantas de girassol.

Quanto maior o teor de B no solo, maior será o teor de $\mathrm{B}$ acumulado pelo caule (BC) e, de maneira similar, maiores o DCAP, a MSF, a MST e maior será a área foliar produzida pela planta de girassol, evidentemente, respeitado o limite da fitotoxidade. Em contrapartida, menores serão os teores de boro acumulados na folha, no capítulo e na raiz do girassol (Tabela 7).

A análise de variância mostrou que não houve significância para o número de folhas e para a altura das plantas, em relação às doses de boro, nem em relação à interação doses de boro e classes de solo (Tabela 8). A ausência de significância estatística, observada para número de folhas por planta, em relação às doses de boro, também foi verificada por Santos Júnior et al. (2011), trabalhando com girassol submetido a doses de boro e diferentes tipos de água de irrigação.

Os resultados aqui descritos em relação à variável altura de plantas são concordantes com os da pesquisa realizada por Wendling \& Gomes (2009), que avaliaram a resposta do girassol à adubação foliar e ao tratamento de

Tabela 5. Médias $(\mathrm{n}=16)$ de teor de boro na folha $(\mathrm{BF})$, teor de boro no caule $(\mathrm{BC})$, teor de boro na raiz $(\mathrm{BR})$, teor de boro no capítulo (BCAP) e conteúdo de boro na massa seca total (BMST), aos 50 DAE em plantas de girassol, cv. Helio 863, em seis classes de solos: Argissolo Acinzentado (PAC); Argissolo Vermelho-Amarelo (PVA); Neossolo Litólico (RL); Argissolo Vermelho eutrófico (PVe); Neossolo Flúvico (RY) e Vertissolo Háplico (VX)

\begin{tabular}{|c|c|c|c|c|c|}
\hline \multirow{4}{*}{ Solos } & \multicolumn{4}{|c|}{ Variáveis } & \multirow{3}{*}{$\begin{array}{c}\text { Conteúdo } \\
\text { BMST }\end{array}$} \\
\hline & \multicolumn{4}{|c|}{ Teor } & \\
\hline & BF & BC & BR & BCAP & \\
\hline & \multicolumn{4}{|c|}{$\mathrm{mg} \mathrm{kg}^{-1}$} & mg planta $^{-1}$ \\
\hline PAC & $125,42 \mathrm{a}$ & $47,41 \mathrm{~b}$ & $108,22 \mathrm{a}$ & $66,78 \mathrm{a}$ & $2,76 \mathrm{~d}$ \\
\hline $\mathrm{PVe}$ & $116,71 \mathrm{a}$ & $49,39 b$ & $96,31 b$ & $68,32 \mathrm{a}$ & $3,58 b$ \\
\hline PVA & $97,84 b$ & $44,19 b$ & $90,33 b$ & $55,64 \mathrm{c}$ & $1,76 \mathrm{e}$ \\
\hline RL & $120,41 \mathrm{a}$ & $61,01 \mathrm{a}$ & $115,29 \mathrm{a}$ & $61,53 b$ & $3,50 \mathrm{~b}$ \\
\hline RY & $96,08 b$ & $58,73 \mathrm{a}$ & $100,44 b$ & $59,99 \mathrm{~b}$ & $3,26 \mathrm{c}$ \\
\hline vX & $96,13 b$ & $58,82 \mathrm{a}$ & $95,22 b$ & $45,56 \mathrm{~d}$ & $4,09 \mathrm{a}$ \\
\hline Erro Padrão & 3,74 & 1,93 & 4,41 & 1,74 & 0,07 \\
\hline
\end{tabular}

Médias seguidas de mesma letra na coluna não diferem entre si pelo teste de Scott-Knott a 5\% de probabilidade. 
Tabela 6. Médias $(\mathrm{n}=16)$ da massa seca da folha (MSF), massa seca do caule (MSC), massa seca da raiz (MSR), massa seca do capítulo (MSCAP) e massa seca total (MST), em g planta-1, aos 50 DAE em plantas de girassol, em seis classes de solos: Argissolo Acinzentado (PAC); Argissolo Vermelho-Amarelo (PVA); Neossolo Litólico (RL); Argissolo Vermelho eutrófico (PVe); Neossolo Flúvico (RY) e Vertissolo Háplico (VX)

\begin{tabular}{lccccc}
\hline \multirow{2}{*}{ Solos } & \multicolumn{5}{c}{ Variáveis } \\
\cline { 2 - 5 } & MSF & MSC & MSR & MSCAP & MST \\
\hline PAC & $8,95 \mathrm{~d}$ & $14,53 \mathrm{e}$ & $6,47 \mathrm{~d}$ & $4,03 \mathrm{e}$ & $34,11 \mathrm{e}$ \\
PVe & $9,18 \mathrm{c}$ & $15,86 \mathrm{~d}$ & $11,75 \mathrm{~b}$ & $8,20 \mathrm{~b}$ & $44,98 \mathrm{~b}$ \\
PVA & $6,33 \mathrm{e}$ & $9,33 \mathrm{f}$ & $4,31 \mathrm{f}$ & $5,96 \mathrm{~d}$ & $26,05 \mathrm{f}$ \\
RL & $8,95 \mathrm{~d}$ & $18,95 \mathrm{~b}$ & $5,89 \mathrm{e}$ & $9,49 \mathrm{a}$ & $43,29 \mathrm{c}$ \\
RY & $9,79 \mathrm{~b}$ & $17,85 \mathrm{c}$ & $7,81 \mathrm{c}$ & $7,64 \mathrm{c}$ & $43,06 \mathrm{~d}$ \\
VX & $11,86 \mathrm{a}$ & $20,38 \mathrm{a}$ & $14,52 \mathrm{a}$ & $9,97 \mathrm{a}$ & $56,91 \mathrm{a}$ \\
\hline Erro Padrão & 0,03 & 0,17 & 0,17 & 0,19 & 0,03 \\
\hline
\end{tabular}

Médias seguidas de mesma letra na coluna não diferem entre si pelo teste de Scott-Knott, a 5\% de probabilidade.

Tabela 7. Coeficiente de correlação de Pearson entre a área foliar (AF) e teor de boro teor de boro na folha (BF), teor de boro no caule (BC), teor de boro no capítulo (BCAP), teor de boro na raiz (BR), diâmetro do capítulo (DCAP), massa seca da folha (MSF), massa seca total e teor de boro no solo (BS), aos 50 DAE em plantas de girassol, cv. Helio 863, cultivadas em seis classes de solos

\begin{tabular}{lcccccccc}
\hline \multirow{2}{*}{ Variável } & BF & BC & BCAP & BR & DCAP & MSF & MST & B S \\
\cline { 2 - 10 } & $-0,17$ & 0,28 & $-0,09$ & $-0,00$ & 0,26 & $0,64^{* *}$ & $0,65^{* *}$ & 0,27 \\
$\mathrm{AF}$ & 10,65 & 0,55 & 34,76 & 92,34 & 0,97 & 0,01 & 0,01 & 0,83 \\
$(\operatorname{Pr}>\mathrm{t})$ & &
\end{tabular}

**significativo ao nível de $1 \%$ de probabilidade pelo teste $\mathrm{F}$.

Tabela 8. Valores de quadrado médio e coeficiente de variação do número de folhas e altura de planta (cm) em plantas de girassol, cv. Helio 863, submetidas a doses de boro em seis classes de solos

\begin{tabular}{|c|c|c|c|c|c|c|c|c|c|}
\hline \multirow{3}{*}{$\begin{array}{l}\text { Fontes de } \\
\text { variação }\end{array}$} & \multirow{3}{*}{ GL } & \multicolumn{4}{|c|}{ Número de folhas } & \multicolumn{3}{|c|}{ Altura de planta } & \\
\hline & & \multicolumn{8}{|c|}{ Dias após emergência - DAE } \\
\hline & & 12 & 24 & 36 & 50 & 12 & 24 & 36 & 50 \\
\hline Blocos & 3 & $2,6^{0}$ & $12,6^{*}$ & $7,2^{0}$ & $2,9^{\text {ns }}$ & $14,4^{*}$ & $32,0^{0}$ & $135,8^{*}$ & $169,2^{\text {ns }}$ \\
\hline Solos (S) & 5 & $8,2^{* *}$ & $53,2^{* *}$ & $48,1^{* *}$ & $80,3^{* *}$ & $32,0^{* *}$ & $252,9^{* * *}$ & $1.161,9^{* *}$ & $1.679,6^{* *}$ \\
\hline DB & 3 & $0,4^{\mathrm{ns}}$ & $1,6^{\mathrm{ns}}$ & $2,4^{\mathrm{ns}}$ & $1,8^{\mathrm{ns}}$ & $5,2^{\mathrm{ns}}$ & $1,6^{\text {ns }}$ & $86,4^{\text {ns }}$ & $164,4^{\text {ns }}$ \\
\hline $\mathrm{S} \times \mathrm{DB}$ & 15 & $1,2^{\mathrm{ns}}$ & $2,7^{\mathrm{ns}}$ & $2,9^{\text {ns }}$ & $3,4^{\mathrm{ns}}$ & $3,0^{\text {ns }}$ & $11,3^{\mathrm{ns}}$ & $57,6^{\mathrm{ns}}$ & $51,0^{\text {ns }}$ \\
\hline Resíduo & 69 & 0,9 & 4,4 & 3,3 & 2,8 & 3,6 & 13,2 & 47,9 & 80,9 \\
\hline C.V. $(\%)$ & & 12,9 & 11,9 & 7,9 & 6,7 & 13,9 & 10,8 & 10,9 & 8,6 \\
\hline Média & & 7,64 & 17,6 & 22,9 & 25,1 & 13,6 & 33,6 & 63,2 & 104,3 \\
\hline
\end{tabular}

ns, ${ }^{0}{ }^{*},{ }^{* *}$ : não significativo; significativo a 10,5 e $1 \%$ pelo teste $\mathrm{F}$. DB = doses de boro.

Tabela 9. Médias ( $\mathrm{n}=16)$ do número de folha e altura de planta $(\mathrm{cm})$ de girassol, em seis classes de solos: Argissolo Acinzentado (PAC); Argissolo Vermelho-Amarelo (PVA); Neossolo Litólico (RL); Argissolo Vermelho eutrófico (PVe); Neossolo Flúvico (RY) e Vertissolo Háplico (VX)

\begin{tabular}{|c|c|c|c|c|c|c|c|c|}
\hline \multirow{3}{*}{ Solos } & \multicolumn{4}{|c|}{ Número de folhas } & \multicolumn{4}{|c|}{ Altura de planta } \\
\hline & \multicolumn{8}{|c|}{ Dias após emergência - DAE } \\
\hline & 12 & 24 & 36 & 50 & 12 & 24 & 36 & 50 \\
\hline PAC & $7,87 \mathrm{~b}$ & $19,06 \mathrm{a}$ & $23,69 \mathrm{a}$ & $25,56 \mathrm{~b}$ & $13,53 b$ & $32,53 \mathrm{c}$ & $56,25 \mathrm{c}$ & $92,81 \mathrm{c}$ \\
\hline PVe & $7,56 b$ & $17,12 b$ & $23,19 \mathrm{a}$ & $24,37 b$ & $11,59 \mathrm{c}$ & $31,87 \mathrm{c}$ & $59,44 \mathrm{c}$ & $103,00 \mathrm{~b}$ \\
\hline PVA & $6,56 \mathrm{c}$ & $14,44 \mathrm{c}$ & $19,37 b$ & $24,94 \mathrm{c}$ & $13,87 \mathrm{~b}$ & $28,56 \mathrm{~d}$ & $58,44 \mathrm{c}$ & $94,00 \mathrm{c}$ \\
\hline RL & $8,69 a$ & $19,62 \mathrm{a}$ & $23,62 \mathrm{a}$ & $26,06 \mathrm{a}$ & $16,00 \mathrm{a}$ & $40,34 \mathrm{a}$ & $78,06 \mathrm{a}$ & $117,75 \mathrm{a}$ \\
\hline RY & $7,25 \mathrm{c}$ & $17,62 b$ & $23,56 \mathrm{a}$ & $27,25 \mathrm{a}$ & $13,41 \mathrm{~b}$ & $32,78 \mathrm{c}$ & $58,25 \mathrm{c}$ & $103,87 b$ \\
\hline VX & $7,94 b$ & $18,00 \mathrm{~b}$ & $23,87 \mathrm{a}$ & $26,31 \mathrm{a}$ & $13,28 b$ & $35,44 \mathrm{~b}$ & $68,91 \mathrm{~b}$ & $114,50 \mathrm{a}$ \\
\hline Erro padrão $(\%)$ & 0,25 & 0,52 & 0,45 & 0,42 & 0,48 & 0,91 & 1,73 & 2,25 \\
\hline
\end{tabular}

Médias seguidas de mesma letra na coluna não diferem entre si pelo teste de Scott-Knott, a 5\% de probabilidade.

Rev. Ceres, Viçosa, v. 61, n.3, p. 399-405, mai/jun, 2014 
sementes, com o micronutriente boro, em Latossolo Vermelho-Escuro. De forma semelhante, Marchetti et al. (2001) verificaram que as alturas de plantas de girassol não diferiram estatisticamente, quando submetidas a diferentes fontes e níveis de boro.

Observou-se ainda que os solos apresentaram efeito significativo, a nível de $1 \%$ de probabilidade, para o número de folhas e altura das plantas, nas diferentes épocas de avaliação (Tabelas 8). Pelo teste de Scott-Knott, o número de folhas e a altura das plantas cultivadas no solo RL foram estatisticamente superiores aos das cultivadas nos demais solos; sendo que os solos PAC, aos 24 e 36 DAE; PVe, aos 36 DAE; RY e VX, aos 36 e 50 DAE foram estatisticamente iguais ao solo RL quanto ao número de folhas produzidas. Em relação à altura de planta, o solo VX foi estatisticamente igual ao solo RL, aos 50 DAE, e o solo PVA foi estatisticamente inferior aos demais, aos 24 DAE; este último apresentou-se ainda estatisticamente inferior aos demais, quanto ao número de folhas em todas as épocas avaliadas e, igual ao solo RY, aos 12 DAE (Tabela 9).

\section{CONCLUSÕES}

A adubação com boro, mesmo considerando diferentes épocas de avaliação, não influenciou as características agronômicas, nem os teores de boro, nas diferentes partes da planta de girassol cv. Hélio 863.

Os solos que mais favoreceram o desenvolvimento das plantas foram o Neossolo Flúvico (RY), o Vertissolo Háplico (VX), o Argissolo Acinzentado (PAC) e o Neossolo Litólico (RL).

\section{REFERÊNCIAS}

Afférri FS, Brito LR, Siebeneichler SC, Peluzio JM, Nascimento LC \& Oliveira TC (2008) Avaliação de cultivares de girassol, em diferentes épocas de semeadura, no sul do Estado do Tocantins, safra 2005/2006. Amazônia: Ciência e Desenvolvimento, 4:79-87.

Aquino LA, Santos Júnior VC, Guerra JVS \& Costa MM (2011) Estimativa da área foliar do girassol por método não destrutivo. Bragantia, 70:832-836.

Bonacin GA (2002) Crescimento de plantas, produção e característica das sementes de girassol em função de doses de boro. Tese de Doutorado. Jaboticabal, Faculdade de Ciências Agrárias e Veterinárias - Unesp. 98p.

Castro C, Moreira, A, Oliveira RF \& Dechen AR (2006) Boro e estresse hídrico na produção de girassol. Ciência Agrotecnologia, 30:214-220.

Dechen AR \& Nachtigall GR (2006) Micronutrientes. In: Fernandes MF (Ed.) Nutrição Mineral de Plantas. Viçosa, Sociedade Brasileira de Ciência do Solo. p.327-354.

EMBRAPA - Empresa Brasileira de Pesquisa agropecuária (1997) Centro Nacional de Pesquisa de Solos. Manual de métodos de análises de solos. $2^{\text {a }}$ ed. Rio de Janeiro, Embrapa - CNPS. 212p. (Documentos, 1).
EMBRAPA - Empresa brasileira de pesquisa agropecuária (2006) Sistema Brasileiro de Classificação de Solos. $2^{\mathrm{a}}$ ed. Rio de Janeiro, Embrapa Solos.

Fagundes JD, Santiago G, Mello AM, Bellé RA \& Streck NA (2007) Crescimento, desenvolvimento e retardamento da senescência foliar em girassol de vaso (Helianthus annuus L.): fontes e doses de nitrogênio. Ciência Rural, 37: 987-993.

Ferreira DF (2000) Análises estatísticas por meio do Sisvar para Windows versão 4.0. In: 45 a Reunião Anual da Região Brasileira da Sociedade Internacional de Biometria, São Carlos. Anais, UFSCar. p.255-258.

Hu H \& Brown PH (1997) Absortion of boron by plant roots. Plant and Soil, 193:49-58.

Lobo TF \& Grassi Filho H (2007) Níveis de lodo de esgoto na produtividade do girassol. Revista Ciencia del Suelo e Nutricíon Vegetal, 7:16-25.

Marchetti, ME, Motomya WR, Fabrício AC \& Novelino JO (2001) Resposta do girassol, Helianthus annuus, a fontes e níveis de boro. Acta Scientiarum, 23:1107-1110.

Monteiro JEBA, Sentelhas PC, Chiavegato EJ, Guiselini C, Santiago AV \& Prela A (2005) Estimação da área foliar do algodoeiro por meio de dimensões e massa das folhas. Bragantia, 64:15-24.

Oliveira JTL, Chaves LHG, Campos VB, Santos Júnior JM \& Guedes Filho DH (2012) Fitomassa de girassol cultivado sob adubação nitrogenada e níveis de água disponível no solo. Revista Brasileira de Agricultura Irrigada, 6:23-32.

Porto WS, Carvalho CGP \& Pinto RJB (2007) Adaptabilidade e estabilidade como critérios para seleção de genótipos de girassol. Pesquisa Agropecuária Brasileira, 42:491-499.

Prado RM \& Leal RM (2006) Desordens nutricionais por deficiência em girassol var. catissol-01. Pesquisa Agropecuária Tropical, 36:187-193.

Raij B van, Andrade JC, Cantarella H \& Quaggio JA (Eds.) (2001) Análise química para avaliação da fertilidade de solos tropicais. Campinas, Instituto Agronômico de Campinas. 285p.

Ribeiro AC, Guimarães PTG \& Alvarez V VH (Eds) (1999) Recomendações para o uso de corretivos e fertilizantes em Minas Gerais. Viçosa, CFSEMG. 359p.

Santos LG, Souza UO, Primo DC, Silva PCC \& Santos AR (2010) Estado nutricional da cultura do girassol submetida à adubação com fósforo e boro. Enciclopédia Biosfera, Centro Científico Conhecer, 6:1-14.

Santos Júnior JA, Gheyi HR, Dias NS, Soares FAL \& Nobre RG (2011) Doses de boro e água residuária na producão do girassol. Revista Ciência Agronômica, 42:857-864.

Sas (2011) SAS/STAT 9.3 User's Guide. Cary, NC: SAS Institute Inc. $8621 \mathrm{p}$.

Smiderle OJ, Mourão Júnior M \& Gianluppi D (2005) Avaliação de cultivares de girassol em savana de Roraima. Acta Amazônica, $35: 331-336$.

Souza A, Oliveira MF \& Castiglioni VBR (2004) O boro na cultura do girassol. Semina: Ciências Agrárias, 25:27-34.

Tedesco MJ, Gianello C, Bissani CA, Bohnen H \& Volkweiss SJ (1995) Análise de solos, plantas e outros materiais. Porto Alegre, Universidade Federal do Rio Grande do Sul. 174p.

Travassos KD, Soares FAL, Gheyi HR, SILVA DRS, NASCIMENTO AKS \& Dias NS (2011) Produção de aquênio de girassol irrigado com água salobra. Revista Brasileira de Engenharia Agrícola e Ambiental, 15:371-376.

Wendling CR \& Gomes LFS (2009) Produtividade do girassol em função da aplicação de boro via tratamento de sementes e foliar. Cultivando o Saber, 2:36-46.

Rev. Ceres, Viçosa, v. 61, n.3, p. 399-405, mai/jun, 2014 